\title{
An echocardiographic study of the interventricular septum in constrictive pericarditis
}

Thomas C. Gibson, William Grossman, Lambert P. McLaurin, Sally Moos, and Ernest Craige From the Division of Cardiology, University of North Carolina School of Medicine, Chapel Hill, North Carolina, and the Division of Cardiology, University of Vermont College of Medicine, Burlington, Vermont, U.S.A.

Ten patients with constrictive pericarditis were studied echocardiographically with specific reference to interventricular septal dynamics. Abnormal movement of the interventricular septum was present in 8 patients and consisted of flattening in systole and unusual posterior motion in diastole. The aetiology of this type of movement is at present unknown but may be related to restriction of normal cardiac rotational dynamics. The interventricular septum also showed diminished degree of thickening (mean 21.2\%). The amplitude of excursion was generally at the upper limit of or greater than normal. Left ventricular posterior wall amplitude of excursion was normal. Flattening of left ventricular posterior wall diastolic movement was seen in 4 patients. Right ventricular end-diastolic dimension was slightly increased $\left(1.2\right.$ to $\left.1.7 \mathrm{~cm} / \mathrm{m}^{2}\right)$ in 5 of 8 patients with abnormal septal motion, but no haemodynamic evidence of diastolic volume overload was found. Posterior pericardial thickening was noted echocardiographically when posterior calcification was present. We conclude that the most common though non-specific feature of the echocardiogram in patients with constrictive pericarditis is abnormal septal motion. Flattening of left ventricular posterior wall diastolic movement, posterior pericardial thickening, and epicardial-pericardial separation may also occur.

Echocardiography has been most useful in pericardial disease for the identification of pericardial effusion, but the value of this method in patients with constrictive pericarditis is not established with any certainty. It is believed that it may be possible to show a thickened pericardium, and that the posterior left ventricular wall may show flat motion during diastole (Feigenbaum, 1972). We report our echocardiographic findings in constrictive pericarditis to show that abnormal interventricular septal motion is an additional feature to be sought in this disorder.

\section{Subjects and methods}

Ten patients, aged 20 to 68 , were studied. All had undergone cardiac catheterization, and a diagnosis of constrictive pericarditis had been made on the basis of characteristic findings (Table 1). The aetiology of the disease was tuberculosis in 5, idiopathic in 4, and following $x$-ray therapy in 1. Pericardial thickening, usually generalized, was confirmed at Received 17 November 1975. operation in 8 patients. Pericardial stripping was sufficiently complete to expect a good functional result after operation. Operation was not performed in the remaining 2 patients but the clinical picture was sufficiently specific to reinforce the catheterization data.

Echocardiographic strip chart recordings were obtained by means of a Smith-Kline Instruments Company Ekoline 20A ultrasonoscope coupled to a Cambridge MC IV multichannel data system. A $7.5 \mathrm{~cm}$ internally focused $2.24 \mathrm{MHz}$ transducer was used; the mitral valve and left ventricular cavity were located by scanning in the standard fashion employed by Feigenbaum et al. (1972). Interventricular septal and left ventricular posterior wall motion were recorded in the region of or below the level of the chordae tendineae. At this level, the mitral valve echo was either fragmented or not seen. Identification of endocardium or epicardium was based on appropriate damping manoeuvres. Simultaneous reference phonocardiograms, using Leatham suction microphones, were also recorded on the strip chart. 
TABLE 1 Summary of cardiac catheterization data

\begin{tabular}{|c|c|c|c|c|c|c|c|}
\hline $\begin{array}{l}\text { Case } \\
\text { No. }\end{array}$ & Age/sex & $\begin{array}{l}\text { Pressures (mm } \mathrm{mg} \text { ) } \\
\text { Right atrium } \\
\text { alv (mean) }\end{array}$ & Right ventricle & $\begin{array}{l}\text { Main pulmonary } \\
\text { artery }\end{array}$ & $\begin{array}{l}P A W \\
a / v \text { mean }\end{array}$ & Left ventricle & $\begin{array}{l}\text { Cardiac index } \\
\left(\text { l/min per } m^{2}\right)\end{array}$ \\
\hline 1 * & $56 \mathrm{~F}$ & $16 / 16(12)$ & $36 / 16$ & $36 / 20$ & $22 / 20(16)$ & $120 / 20$ & $2 \cdot 0$ \\
\hline $2 \star$ & $20 \mathrm{~F}$ & $20 / 20(18)$ & $36 / 20$ & $36 / 20$ & $24 / 32$ & $110 / 22$ & 2.5 \\
\hline $3 \star$ & $65 \mathrm{M}$ & $23 / 20$ (17) & $39 / 16$ & $39 / 17$ & $17 / 20$ (18) & $124 / 24$ & 2.9 \\
\hline $4 \dagger$ & $56 \mathrm{M}$ & $30 / 25(26)$ & $50 / 28$ & $50 / 28$ & $28 / 28(24)$ & $140 / 28$ & $2 \cdot 7$ \\
\hline $5 \star$ & $40 \mathrm{M}$ & $16 / 15$ (14) & $29 / 15$ & $29 / 15$ & $20(16)$ & $100 / 16$ & 2.0 \\
\hline $6 \star$ & $32 \mathrm{M}$ & $22 / 14$ (18) & $28 / 17$ & $28 / 19$ & $27 / 20$ (18) & - & 2.0 \\
\hline 7 & $58 \mathrm{M}$ & $20 / 18(18)$ & $44 / 17$ & $44 / 17$ & $25 / 22(18)$ & $90 / 18$ & $2 \cdot 9$ \\
\hline 8 & $68 \mathrm{M}$ & $20 / 20$ (18) & $38 / 17$ & $38 / 20$ & $20 / 16$ (18) & $130 / 20$ & 2.0 \\
\hline $9 \star$ & $53 \mathrm{M}$ & $18 / 18(16)$ & $26 / 16$ & $26 / 16$ & $23 / 14$ (16) & - & 1.7 \\
\hline $10 *$ & $26 \mathrm{M}$ & $18 / 15$ (14) & $30 / 14$ & $30 / 16$ & $18 / 20$ (14) & $110 / 16$ & 2.0 \\
\hline
\end{tabular}

$\star$ =operated; $\dagger=$ died after operation; $a / v=$ peak $a /$ peak $v . P A W=$ Pulmonary artery wedge.

Conversion from Traditional Units to SI Units: $1 \mathrm{mmHg} \approx 0.133 \mathrm{kPa}$.

The following measurements were made:

(1) Interventricular septal mimimum and maximum thickness, percentage change in thickness, and amplitude of excursion.

(2) Left ventricular posterior wall amplitude of excursion.

(3) Right ventricular dimension index using the method described by Diamond et al. (1971).

All measurements were made to the nearest $\mathrm{mm}$, and were a mean of 5 readings. Pre- and postoperative tracings were obtained at comparable heart rates with no more than 10 beats per minute difference.

\section{Results}

\section{Interventricular septum}

The echocardiographic data are summarized in Table 2.

(A) Septal motion (1) Systolic: Normal septal movement as recorded may be briefly anterior after the onset of the QRS complex, but the main direction is posterior with a maximal displacement reached just before maximal anterior movement of the left ventricular posterior wall. Posterior septal movement did take place in 6 of 10 patients (Cases $1,6,7,8,9$, and 10), but was diminished and atypical in 3 of these 6 (Cases 1, 6, and 8). In Cases

TABLE 2 Summary of interventricular septal echocardiographic data

\begin{tabular}{|c|c|c|c|c|c|c|}
\hline $\begin{array}{l}\text { Case } \\
\text { No. }\end{array}$ & Age/Sex & Movement & $\begin{array}{l}\text { Minimal thickness } \\
(\mathrm{mm})\end{array}$ & $\begin{array}{l}\text { Maximal thickness } \\
(\mathrm{mm})\end{array}$ & $\%$ change & $\begin{array}{l}\text { Amplitude of } \\
\text { excursion ( } \mathrm{mm} \text { ) }\end{array}$ \\
\hline $\begin{array}{r}1 \\
2 \\
3 \\
4 \\
5 \\
6 \\
7 \\
8 \\
9 \\
10 \\
\end{array}$ & $\begin{array}{l}56 \mathrm{~F} \\
20 \mathrm{~F} \\
65 \mathrm{M} \\
56 \mathrm{M} \\
40 \mathrm{M} \\
32 \mathrm{M} \\
58 \mathrm{M} \\
68 \mathrm{M} \\
53 \mathrm{M} \\
26 \mathrm{M} \\
\end{array}$ & $\begin{array}{l}\mathbf{A}(\mathbf{A}) \\
\mathbf{A}(\mathbf{A}) \\
\mathbf{A}(\mathbf{A}) \\
\mathbf{A} \\
\mathbf{A}(\mathbf{A}) \\
\mathbf{A}(\mathbf{A}) \\
\mathbf{A} \\
\mathbf{A} \\
\mathbf{N}(\mathbf{A}) \\
\mathbf{N}(\mathbf{N})\end{array}$ & $\begin{array}{r}10 \\
8 \\
10 \\
11 \\
8 \\
10 \\
7 \\
7 \\
8 \\
11\end{array}$ & $\begin{array}{r}12 \\
10 \\
11 \\
12 \\
9 \\
12 \\
9 \\
10 \\
10 \\
13\end{array}$ & $\begin{array}{r}20 \\
25 \\
10 \\
9 \\
13 \\
20 \\
29 \\
43 \\
25 \\
18\end{array}$ & $\begin{array}{c}8(8) \\
8(7) \\
7(6) \\
9 \\
10(7) \\
8(8) \\
8 \\
9 \\
8(7) \\
6(8)\end{array}$ \\
\hline $\begin{array}{l}\text { No. } \\
\text { Range } \\
\text { Mean } \\
1 \text { SD } \\
1 \text { SE }\end{array}$ & & & $\begin{array}{l}(10) \\
7-11 \\
9 \cdot 0 \\
1.56 \\
0.49\end{array}$ & $\begin{array}{l}(10) \\
9-13 \\
10 \cdot 8 \\
1 \cdot 40 \\
0 \cdot 44\end{array}$ & $\begin{array}{l}(10) \\
10-43 \\
21 \cdot 2 \\
10 \cdot 10 \\
3 \cdot 19\end{array}$ & $\begin{array}{l}(10) \\
6-10 \\
8 \cdot 1 \\
1 \cdot 10 \\
0 \cdot 37\end{array}$ \\
\hline
\end{tabular}

$\mathrm{N}=$ normal; $\mathrm{A}=$ =abnormal; $\mathrm{SD}=$ standard deviation; $\mathrm{SE}=$ standard error.

Data obtained after operation are shown in brackets. 




FIG. 1 An example of abnormal interventricular septal motion from Case 4. Simultaneous phonocardiogram and lead II electrocardiogram. The vertical arrows emphasize the paradoxical motion of the septum. $C=$ chordas. ENDO=endocardiun. EPI=epicardium. $L S=$ left side of the interventricular system. $L V=$ left ventricular cavity. PERI=pericardium.

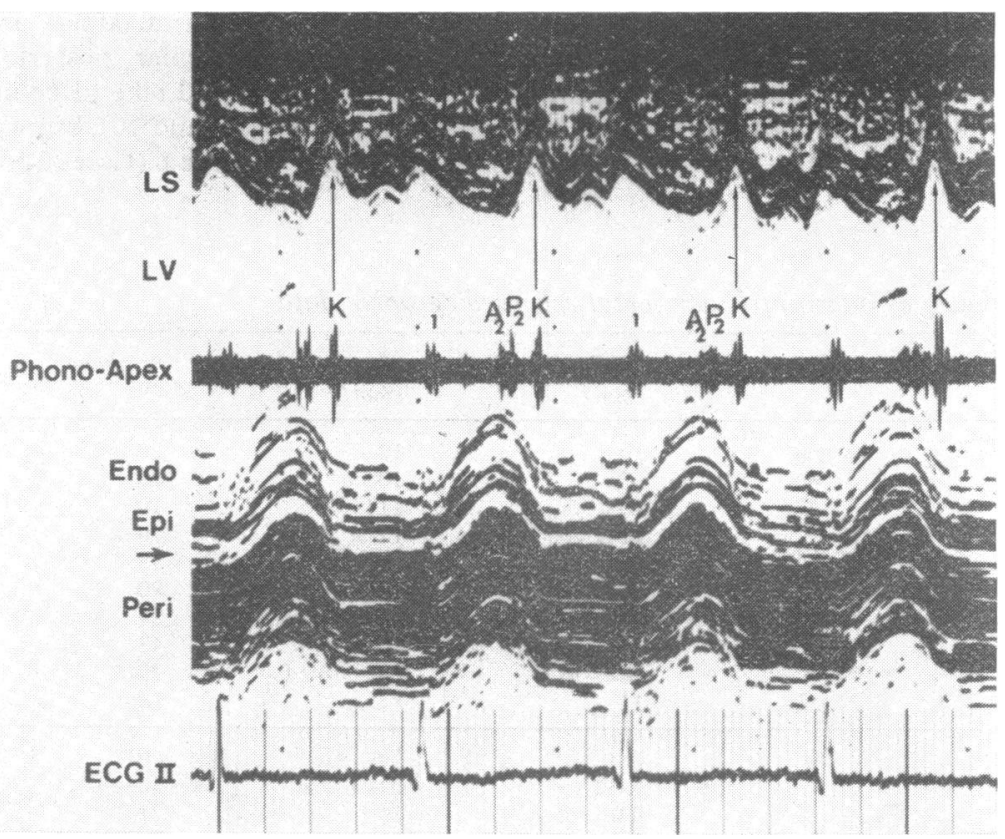

FIG. 2 Left ventricular cavity in Case 7. A gap between the epicardium and pericardium is seen (horizontal arrow). A simultaneous apical phonocardiogram shows that the pericardial knock sound $(K)$ coincides with a sharp reversal of interventricular septal movement (vertical arrows). 
FIG. 3 (a) Traced schematic representations of septal and left ventricular posterior wall movement in Cases 1 to 10. The onset and termination of the tracings are from peak to peak of the $R$ wave of the electrocardiogram. The vertical arrow indicates the onset of the aortic component of the second sound. The amplitudes of wall motion are not directly comparable since the scales were different. (b) Traced, schematic representations of the postoperative data obtained in those cases that were studied.

$2,3,4$, and 5 , movement was anterior, biphasic, and flattened.

(2) Diastolic: After the second sound, three types of septal motion were seen. In group 1 (Cases 1-4), a major degree of posterior movement occurred immediately after the second sound (Fig. 1). In Group 2 (Cases 5-8), immediately after the second sound, there was either anterior or no motion followed by posterior motion at the end of rapid ventricular filling (Fig. 2). This type of posterior motion appeared as an exaggeration and persistence of the usually minor transient posterior motion seen in normal people at this time. In group 3 (Cases 9 and 10) the degree of movement was not sufficient to call definitely abnormal, but the expected asynchrony of maximal end-systolic septal and posterior wall movement was not apparent. In none of the 10 patients did the onset of posterior movement coincide with atrial systole.

(B) Postoperative septal motion It was possible to compare pre- and postoperative septal motion in 7 patients. The abnormal motion persisted in 5 and first appeared postoperatively in 1 (Case 9). In Case 10, posterior systolic movement of the septum was increased.

Fig. $3 a$ and $3 b$ show in diagrammatic form the movement of the left side of the interventricular septum and the left ventricular posterior wall preand postoperatively for the whole group of patients.

(C) Septal thickness Minimal septal thickness ranged from 7 to $11 \mathrm{~mm}$, with a mean of $9.0 \mathrm{~mm}$. These data are within the normal limits of our laboratory. Maximal septal thickness ranged from 9 to $13 \mathrm{~mm}$, with a mean of $10 \cdot 8 \mathrm{~mm}$. This mean could indicate abnormal thinness since the normal range of our laboratory is 10 to $16 \mathrm{~mm}$ with a mean of $13.5 \mathrm{~mm}$. However, only 2 patients fell outside the lower limit of normal. The mean percentage change in thickness of 21.2 per cent is reduced since vur normal data range from 25 to 40 per cent, and 6 of the 10 patients are below normal.
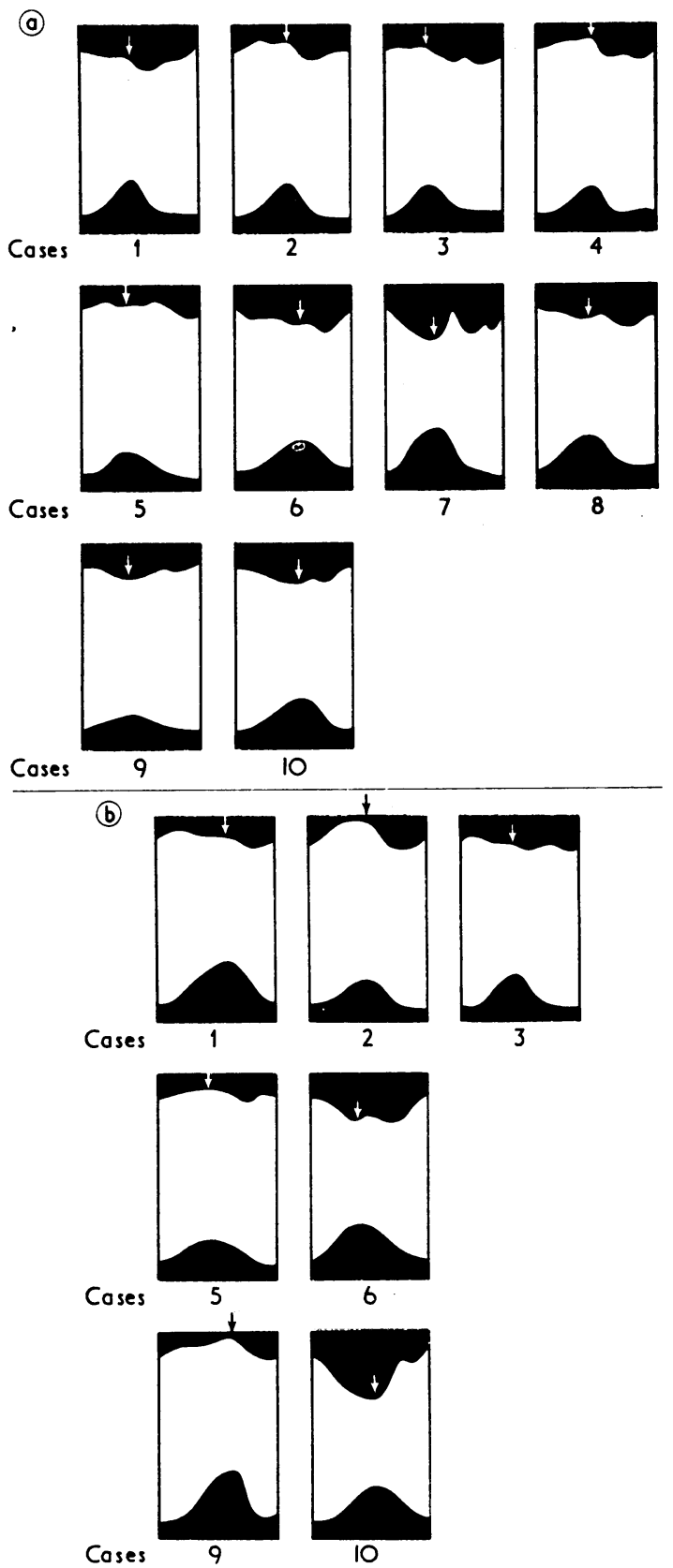

(D) Amplitude of excursion The range for this measurement was 6 to $10 \mathrm{~mm}$, with a mean of $8.1 \mathrm{~mm}$. Our normal range is 3 to $8 \mathrm{~mm}$ so that 5 patients were at the uppermost limit of normal and 3 were in the hyperkinetic range. 


\section{Left ventricular posterior wall}

(A) Left ventricular posterior wall movement The pattern of left ventricular posterior wall endocardial diastolic movement was abnormally flat in 4 patients (Cases 1, 2, 3, and 4), and conformed to a previous observation by Feigenbaum (1972). One of these (Case 4) also showed slight late anterior motion in diastole. These observations are illustrated in Fig. 3A.

(B) Left ventricular posterior wall amplitude of excursion The range for this measurement was 9 to $11 \mathrm{~mm}$, with a mean of $10.1 \mathrm{~mm}$. This is within normal limits.

\section{Right ventricular dimension index}

Mean right ventricular dimension index was 1.2 $\mathrm{cm} / \mathrm{m}^{2}$ (range 0.5 to 1.7 ). This mean is the upper limit of normal for our laboratory, and in 5 patients this index was above normal.

\section{Discussion}

The principal echocardiographic feature of constrictive pericarditis in this study was abnormal interventricular septal motion. Anomalies of technique cannot be responsible for this since the observations were made at or below the level of the chordae tendineae. Hagan et al. (1974) have described the type of septal motion usually found in normal subjects at this level, which does not correspond in contour to that seen in 8 of the 10 patients studied. The character of the abnormal septal motion was variable though it most consistently resembled the B type described by Diamond et al. (1971). Thus, constrictive pericarditis must now be added to the growing list of disorders that are associated with this phenomenon.

The mechanism of this abnormal septal motion is obscure, and the established causes recently reviewed by Assad-Morell, Tajik, and Giuliani (1974) were not present. No electrocardiographic evidence of intraventricular conduction abnormalities, specifically left bundle-branch block, was noted. There was no evidence of cardiomyopathy or coronary artery disease. A right ventricular dimension index increase was found in $\mathbf{5}$ of $\mathbf{8}$ patients with abnormal septal motion but this was not of the degree usually seen in atrial septal defect or other conditions with right ventricular diastolic overload. Nevertheless the possibility of right ventricular diastolic overload could not be excluded. In order to study this further, simultaneous equisensitive right and left ventricular pressure records were obtained in one patient with normal septal motion (Case 10), who had the lowest right ventricular dimension index $\left(0.5 \mathrm{~cm} / \mathrm{m}^{2}\right)$ and in one patient (Case 3 ) with the highest right ventricular dimension index $\left(1.7 \mathrm{~cm} / \mathrm{m}^{2}\right)$. It was not possible in either patient to show interventr:cular pressure gradients in diastole. This suggests that the abnormal septal movement in constrictive pericarditis is not caused by right ventricular overload, since very small changes in right ventricular diastolic volume result in great increases in right ventricular diastolic pressure in this condition (Lewis and Gotsman, 1973). Respiration did not affect septal motion; since the degree of ventricular filling in constrictive pericarditis is not influenced by respiration, this is not surprising (Shabetai, Fowler, and Guntheroth, 1970).

At present any explanation of the abnormality found is hypothetical. The usual rotational character of ventricular movement with pivoting about the septum might be altered by fixation and relative immobility of the anterior cardiac surface. Adherence of the pericardium to the sternum or to the pleura was common at operation; this finding could explain a difference in the normal recording of the upper half of the interventricular septum with respect to the fixed position of the ultrasonic transducer. The range of abnormality of septal movement found may reflect the degree of adhesion, though the latter could not be quantified. A further relevant observation may be that we have not seen this type of abnormal septal motion in the only 3 patients with restrictive cardiomyopathy that we have studied by echocardiography. Apparent changes in interventricular septal thickness and movement might be the result of an unusual angle of incidence of the transducer beam. We propose to study septal mechanics by means of biventricular angiography, using the technique described by Redwood, Scherer, and Epstein (1974).

The persistence after operation of abnormal septal motion in our patients is most probably related to the type of incision used, since this echocardiographic finding has been noted in patients who have had median sternotomy for other cardiac disorders (Burggraf and Craige, 1975). This could also result from fixation of the anterior cardiac surface, though there are no experimental data on this point.

Left ventricular posterior wall diastolic movement was occasionally flat as has been reported by Feigenbaum (1972). This is primarily an epicardial and pericardial phenomenon though endocardial flattening was also seen. We would attribute this to decrease in ventricular compliance with little left ventricular filling occurring after the early diastolic rapid filling phase. This is not a finding confined to constrictive pericarditis since it has been seen in 
patients with other types of left ventricular pathology that diminish compliance.

Other epicardial and pericardial abnormalities have been seen in echocardiographic recordings. These include apparent thickening of the posterior pericardium, producing a single dense band of echoes (Feigenbaum, 1972). In addition two equally intense, parallel moving echoes, separated by a distance of 1 to $3 \mathrm{~mm}$ from the region of the posterior parietal surface of the visceral pericardium, were reported in patients with pericardial thickening (Horowitz et al., 1974). Such findings were present in Case 7 who also had the most striking posterior calcification radiologically, and in Case 10 who also had posterior calcification. In our other patients, posterior thickening and a definite separation of the type described were technically difficult to define, and therefore not diagnostically helpful.

It is resonable to conclude, on the basis of the current findings, that the echocardiographic diagnosis of constrictive pericarditis will usually be by exclusion. Abnormal septal motion lacks specificity but may have high sensitivity. Flattening of the posterior left ventricular wall diastolic motion may be neither sufficiently specific nor sensitive. Obvious thickening of the posterior left ventricular wall lacks sensitivity but may be specific for calcific pericarditis. Nevertheless, a combination of echocardiographic findings, in conjunction with the clinical situation, may alert the physician to the possibility of this condition which may be difficult to diagnose.

\section{References}

Assad-Morell, J. L., Tajik, A. J., and Giuliani, E. R. (1974). Echocardiographic analysis of the ventricular septum. Progress in Cardiovascular Diseases, 17, 219.

Burggraf, G. W., and Craige, E. (1975). Echocardiographic studies of left ventricular wall motion and dimensions after valvular heart surgery. American fournal of Cardio$\log y, 35,473$.

Diamond, M. A., Dillon, J. C., Haine, C. L., Chang, S., and Feigenbaum, H. (1971). Echocardiographic features of atrial septal defect. Circulation, 43, 129.

Feigenbaum, H. (1972). Echocardiography, pp. 183-186. Lea and Febiger, Philadelphia.

Feigenbaum, H., Popp, R. L., Wolfe, S. B., Troy, B. L., Pombo, J. F., Haine, C. L., and Dodge, H. T. (1972). Ultrasound measurements of the left ventricle: a correlative study with angiocardiography. Archives of Internal Medicine, 129, 461.

Hagan, A. D., Francis, G. S., Sahn, D. J., Karliner, J. S., Friedman, W. F., and O'Rourke, R. A. (1974). Ultrasound evaluation of systolic anterior septal motion in patients with and without right ventricular volume overload. Circulation, 50, 248.

Horowitz, M. S., Rossen, R. M., Harrison, D. C., and Popp, R. L. (1974). Ultrasonic evaluation of constrictive pericardial disease (abstract). Circulation, 50, III 87.

Lewis, B. S., and Gotsman, M. S. (1973). Left ventricular function in systole and diastole in constrictive pericarditis. American Heart fournal, 86, 23.

Redwood, D. R., Scherer, J. L., and Epstein, S. E. (1974). Biventricular cineangiography in the evaluation of patients with asymmetric septal hypertrophy. Circulation, 49, 1116.

Shabetai, R., Fowler, N. O., and Guntheroth, W. G. (1970). The hemodynamics of cardiac tamponade and constrictive pericarditis. American fournal of Cardiology, 26, 480.

Requests for reprints to Dr. Thomas C. Gibson, Division of Cardiology, Medical Center Hospital of Vermont, Burlington, Vermont 05401, U.S.A. 